\title{
EFFECT OF TIMEPIDIUM BROMIDE, AN ANTICHOLINERGIC AGENT, ON GASTRIC AND DUODENAL BLOOD FLOW DISTRIBUTION IN RABBITS
}

\author{
Kazuaki NAITO, Minezo OTSUKA and Shoichi HARIGAYA \\ Pharmacological Research Laboratory, Tanabe Seiyaku Co.. Ltd. \\ Toda, Saitama 335, Japan
}

Accepted October 15, 1981

\begin{abstract}
Effects of timepidium bromide (TB; anticholinergic agent), acetylcholine (ACh) and neostigmine (Neost) on gastric and duodenal blood flow distribution were studied by the use of 131/-labeled macroaggregated human serum albumin (MAA) in rabbits. In normal rabbits, gastric blood flow was found to be uneven in various regions of the stomach anterior corpus ( $50 \%$ of total gastric blood flow) $>$ posterior corpus $(40 \%)>$ pyloric antrum (7\%). Intravenous administration of TB $(200 \mu \mathrm{kg} / \mathrm{kg})$ to normal rabbits produced a slight increase in total gastric blood flow, but the increase in the mucosal layer of the pyloric antrum was considerable. On the other hand. ACh $(10 \mu \mathrm{g} / \mathrm{kg}$, i.v. $)$ and Neost $(50 \mu \mathrm{g} / \mathrm{kg}$, i.v.) significantly reduced the total gastric blood flow, in particular, the mucosal blood flow in the anterior and posterior corpus. This reduction in blood flow was virtually abolished by TB and was restored to the normal level. These results suggest that these cholinergic or anticholinergic drugs affect the gastric blood flow and that these effects may be mediated through muscarinic receptors. Blood flow in the duodenum was only slightly changed by these drugs.
\end{abstract}

1,1-Dimethyl-5-methoxy-3-(dithien-2ylmethylene) piperidinium bromide, timepidium bromide (TB), has a potent spasmolytic activity on the gastrointestinal tract, gallbladder and urinary bladder $(1,2)$ and also possesses anti-ulcerogenic effects in animals (3) and man (4).

Gastric ulcer can be induced by the impairment of mucosal blood flow in the stomach and the subsequent aggression of gastric acid and pepsin on the weakened mucosa (5). Goldman and Rosoff (6) suggested that stress ulceration may be caused by ischemic changes in the gastric mucosa due to muscular contractions and extrinsic compression of intramural vessels leading to degeneration of the mucosal cells. In their view it would be desirable for an anti-ulcerogenic agent to increase the gastric blood flow. We therefore examined effects of TB and two commonly used cholinergic drugs, acetylcholine and neostigmine, on blood flow distribution in the stomach and duodenum of rabbits.

Quantiative determinations of blood flow distribution were made using the $131 \%$. macroaggregated human serum albumin method $(7,8)$.

\section{MATERIALS AND METHODS}

Fifty-two male Japanese White rabbits, ranging from 3.2 to $3.5 \mathrm{~kg}$ in body weight. were used to measure the regional blood flow distribution and to prepare auto- 
radiograms. Two male Sprague-Dawley rats weighing about $250 \mathrm{~g}$ were also used for whole body autoradiography $(9,10)$ to confirm the trapped proportion of injected 1.311-MAA in the microcirculation. Food and water were provided ad libitum before start of the experiments.

Determination of blood flow distribution in normal rabbits: Blood flow distribution was determined by the 1311 -macroaggregated human serum albumin method described by Ueda et al. (7) and Asano et al. (8) with some modification.

Under ether anesthesia, catheters were placed into the left ventricle of the heart through the common carotid artery and in the femoral vein. In all experiments, the rabbits were used 30 min after cessation of these procedures.

In the control experiment, $0.5 \mathrm{ml}$ of saline was given into the femoral vein over a $30 \mathrm{sec}$ period, and 5 min later, ${ }^{131} 1$-MAA (100 $/ \mathrm{C}$. $250 \mathrm{~kg}$ as albumin, $10-50 \mu \mathrm{m}$ in diameter) suspended in $6 \%$ dextran was injected into the left ventricle during a 10 to $20 \mathrm{sec}$ period. Ten minutes after injection of 1311 MAA, the animals were sacrificed with an overdose of pentobarbital sodium, and the stomach and other organs were quickly removed and weighed.

Blood flow distribution was measured by counting the radioactivity in the organs and was expressed as percent of the total radioactivity injected, which represents the distribution ratio of regional blood flow to the cardiac output. The Student's t-test was used to assess the statistical significance of alterations in blood flow.

Determination of blood flow distribution in drug-treated rabbits: Acetylcholine (ACh, $10 \mathrm{\prime g} / \mathrm{kg}$ ) or neostigmine (Neost, $50 \mathrm{\prime g} / \mathrm{kg}$ ) was administered from the femoral vein over a 30 sec period. 131/-MAA was injected into the left ventricle of rabbits 2 min after $A C h$ or $5 \mathrm{~min}$ after Neost. TB $(200 / / \mathrm{g} / \mathrm{kg})$ was injected into the femoral vein 5 min prior to 131I-MAA. Subsequent procedures were as described above.

To evaluate the effects of TB on gastric and duodenal blood flow in cholinergic drug-treated animals. TB was administered in a dose of $200 \mathrm{rg} / \mathrm{kg}$ through the femoral vein $3 \mathrm{~min}$ before $\mathrm{ACh}$ or $5 \mathrm{~min}$ after Neost 131--MAA was given into the left ventricle of the animals $2 \mathrm{~min}$ after $\mathrm{ACh}$ and $10 \mathrm{~min}$ after Neost.

Dissection of the gastric and duodenal walls and measurement of the radioactivity: The stomach was incised along the greater curvature and divided into 9 segments as shown in Fig. 1 (anterior corpus $\mathrm{Ca}=\mathrm{V}_{1}+\mathrm{V}_{2}+$ $V_{3}$, posterior corpus $\mathrm{Cp}=\mathrm{H}_{1}+\mathrm{H}_{2}+\mathrm{H}_{3}$, pyloric antrum $P y \mid=P_{1}+P_{2}+P_{3}$ ) according to the method of Asano et al. (8). All segments were then separated into mucosal and muscular layers by scraping off the mucosa from the underlying submucosa with a spatula. Microscopic observation showed that the mucosal and muscular layers were almost completely separated from each other.

Each segment of the gastric mucosa and muscle was put into a plastic tube, and the

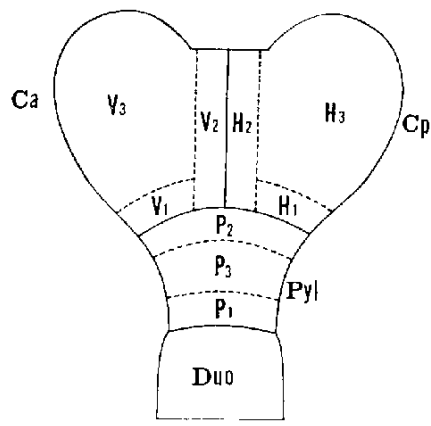

Fig. 1. The stomach and duodenum of rabbit were incised along the greater curvature, and the slomach was divided into nine segments. Each scgment of the gastric wall was separated into the mucosal and muscular layers. Ca $\left(V_{1}+V_{2} \div\right.$ $\left.V_{3}\right)$ : Anterior Wall of Corpus Ventriculi. Cp $\left(\mathrm{H}_{1}+\mathrm{H}_{2}, \mathrm{H}_{3}\right)$ : Postorior Wall of Corpus Ventriculi. $P y \mid\left(P_{1}+P_{2}+P_{3}\right)$ : Pyloric Antrum. Duo: Duodenum. 
radioactivity was counled using a gamma spectrometer (Aloka, JDC-751). Radioactivity in the duodonum was moasured as total counts in the mucosal and muscular layers because it was difficult to separate them from each other.

Autoradiographic distribution of $1311-\mathrm{MAA}$ : Two rats were administered $50 / \mathrm{Cl}$ of $131 \mathrm{I}$ MAA (125 $/ \mathrm{g}$ as albumin) intravenously. Ten minutes later, the animals were anesthetized with ether and frozen in dry iceacetone. Saggital sections, $40 \mathrm{~km}$ thick, were cut from the frozen animals using an Autocryotome (NA-200F). The sections were then freeze-dried, placed in contact with $X$ ray films (Kodak NS-5T), and kept at $5^{\circ}$ for 7 days for exposure. The autoradiograms wore then obtained after the development and fixation.

Two normal rabbits were injected with $100 " \mathrm{Ci}$ of $131 /-\mathrm{MAA}$ (250 $/ \mathrm{g}$ as albumın) into the left ventricle and killed $10 \mathrm{~min}$ later. Tho stomach and duodenum were excised. fixed and incised along the greater curvature. Flat mount preparations of the stomach and duodenum were obtained by extending them on a plate. They were successively passed through 70,80,90 and 100\% ethanol, airdried and placed in contact with the films.

Materials: The compounds used were TB (Sesden, Tanabe), acetylcholine (Ovisot, Daiıchi), neostigmine and pentobarbital (Nakarai), and 131-labeled macroaggregated human serum albumin (131-MAA, Daiichi Radioisotope Labs.). All compounds except 1311-MAA were dissolved in physiological saline. 131/-MAA was suspended in 6\% dextran-saline solution (Macrodex. Green Cross Corp.).

\section{RESULTS}

\section{Autoradiographic distribution of 131/-MAA}

After i.v. administration of 131/-MAA to rats, the radioactivity was located only in the lung, and it was apparent that 131/-MAA was trapped in the capillaries or small arterioles of the lung (Fig. 2).

Figure 3 shows a typical autoradiogram of the mucosal surfaces of the stomach and duodenum after ventricular injection of 1311
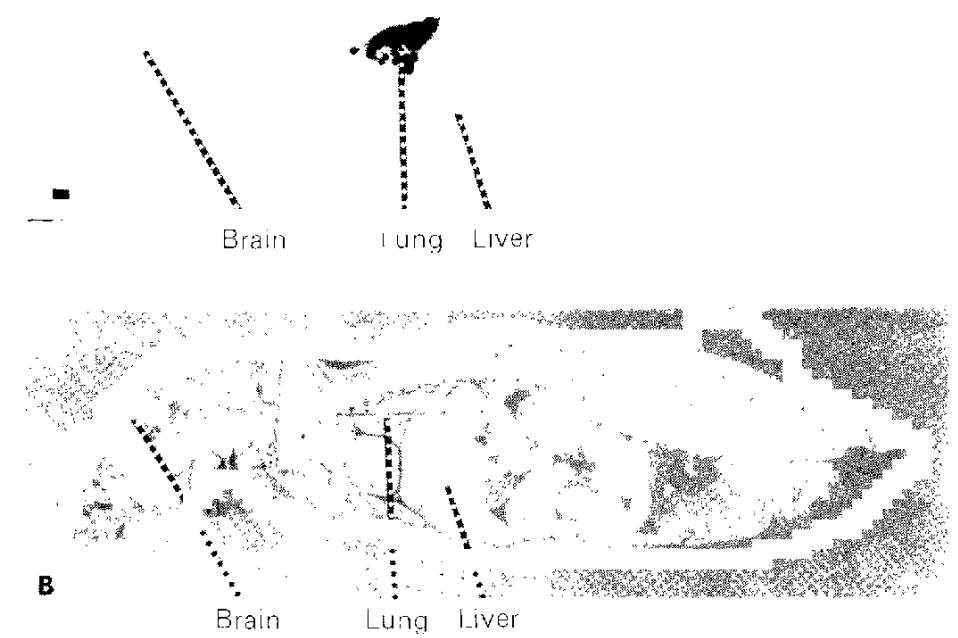

Fig. 2. Autoradiogram showing the distrbution of 1311 radioactivity 10 min after intravenous injection of 131 I-MAA to a rat. A: Autoradiogram. B: Corresponding tissue section. 
MAA to normal rabbits. The highest radioactivity was in the corpus, followed by the radioactivity in the duodenum, and the lowest in the pyloric antrum. Within the corpus, the radioactivity in the anterior wall

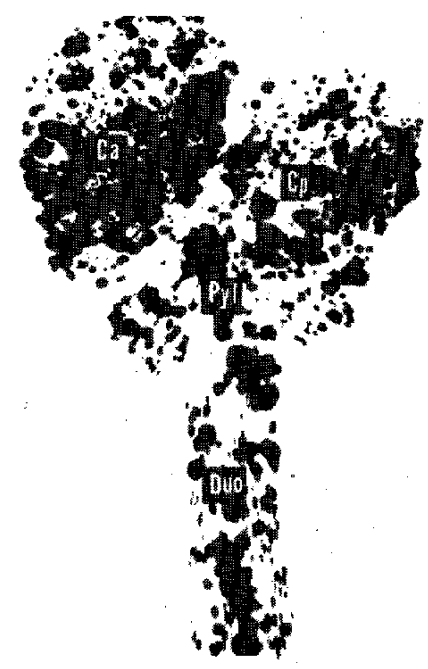

Fig. 3. Autoradiogram showing the distribution of 1311 radioactivity in the mucosal surface of the gastric and duodenal walls of the control rabbif 10 mir after injoction of $13: 1-M A A$ into the left ventricle of the heart. was slightly higher than that in the posterior wall.

Gastric blood flow distribution in normal rabbits (control experiments)

Blood flow distribution in the stomach and some other organs of control rabbits treated with saline was estimated by the use of 131/-MAA. Blood flow distribution (hereafter denoted as blood flow) is represented by percent of the cardiac output. Blood flows of the stomach and other organs are shown in Table 1. These values are similar to those obtained by the radioactive microsphere techniuue (11).

As shown in Table 2, the anterior corpus was supplied with the largest share of the total gastric blood flow, about $50 \%$, and the posterior corpus with about $40 \%$. Only $7 \%$ of the total gastric flow was distributed in the pyloric antrum. Blood flows per gram of wet tissue of the stomach and duodenum are also shown in Table 2. The blood flow in the pyloric antrum was much lower than those in the corpus $(P<0.05)$ and duodenum $(P<0.1)$. A slight difference in blood flow

Table 1. Blood flows (\% of the cardiac output) of the various organs of the control rabbits

\begin{tabular}{|c|c|c|c|c|c|c|}
\hline & Storrach & Heart & Liver & Kidney & Lung & Spleen \\
\hline $1311-M A A^{11}:$ & $3.31 \pm 0.39$ & $3.22 \pm 0.45$ & $5.19 \pm 0.69$ & $11.98 \pm 1.40$ & $7.11 \pm 0.85$ & $0.42 \pm 0.09$ \\
\hline Microsphere & $3.4(1.7-5.5)$ & $3.1(2.1-4.5)$ & $\left.3.4(0.9-9.1)^{0}\right)$ & $16.2(11.6-21.4)$ & - & $1.8(1.1-3.0)$ \\
\hline
\end{tabular}

a) Values represent the mean and S.E. of 8 animals. b) Quoted from Reference 11). The data represent the mean of 20 rabbits and figures in parentheses denote the range of 10-90 percontile. c) Arterial Blood Flow.

Table 2. Gastric and duodenal blood flow distribution in control rabbits

\begin{tabular}{|c|c|c|}
\hline Regions & $\begin{array}{l}\text { Blood Flow (\% of C.O.) } \\
\text { in Whole Tissues }\end{array}$ & $\begin{array}{l}\text { Blood Flow (\% of C.O.) } \\
\text { ing of Tissues }\end{array}$ \\
\hline Stomach & $3.31 \pm 0.39$ & $0.16 \pm 0.02$ \\
\hline Anterior Corpus & $1.74 \pm 0.23^{* * *}$ & $0.22 \pm 0.03^{* * *}$ \\
\hline Posterior Corpus & $1.34 \pm 0.15^{* * *}$ & $0.19 \pm 0.02^{* *}$ \\
\hline Pyloric Antrum & $0.23 \pm 0.05$ & $0.04 \pm 0.01$ \\
\hline Duodenum & $0.42 \pm 0.11$ & $0.11 \pm 0.02^{*}$ \\
\hline
\end{tabular}

Values ropresent the mean and S.E. of 8 animals. ${ }^{*} P<0.1,{ }^{*} P<0.05,{ }^{* *} P<0.01$ compared with the value of the antrum. C.O.: Cardiac Output, 
between the anterior and posterior corpus was also observed. Within the corpus, the blood flows in the border regions $\left(V_{1}, V_{2}\right.$. $H_{1}, H_{2}$ ) were somewhat less than those in the principal regions $\left(\mathrm{V}_{3} . \mathrm{H}_{3}\right)$, but the pyloric antrum seems to show no obvious difference in blood flow between the three segments $P_{1}, P_{2}$ and $P_{3}$ (Fig. 4). It was thus revealed that gastric blood flow was unevenly distributed in the stomach in terms of both total blood flow and blood flow per $g$ of tissue.

Since the mucosal layer plays an important role in the microcirculatory system of the stomach, the blood flows in the mucosal and muscular layers of the stomach were individually estimated. As shown in Table 3. the mucosal blood flow was far greater than that of the muscular layer.

\section{Effects of the drugs on gastric blood flow}

Cholinergic drugs: Treatment with $\mathrm{ACh}$
(10 $/ \mathrm{gg} / \mathrm{kg}$, i.v.) significantly reduced the total gastric blood flow from the control levels ( $P<0.05)$. In particular, the mucosal blood flow decreased both in the anterior and posterior corpus $(P<0.05$. Fig. 5 ).

Intravenous administration of Neost to normal rabbits also reduced the total gastric blood flow. As shown in Fig. 5, the mucosal blood flow in the anterior corpus was markedly reduced. When compared with $A C h$, the effect of Neost on the total gastric blood flow was less in degree.

Timepidium bromide (TB): When TB was administered $i . v$. in a dose of $200 \mu \mathrm{g} / \mathrm{kg}$. TB caused a slight increase in total gastric blood flow (Fig. 5). TB increased the mucosal blood flow in the posterior corpus and the pyloric antrum. The increase in the pyloric antrum was significant. In detailed regions, the TB-treated group showed increased blood flow especially in $P_{1}$ of the pyloric

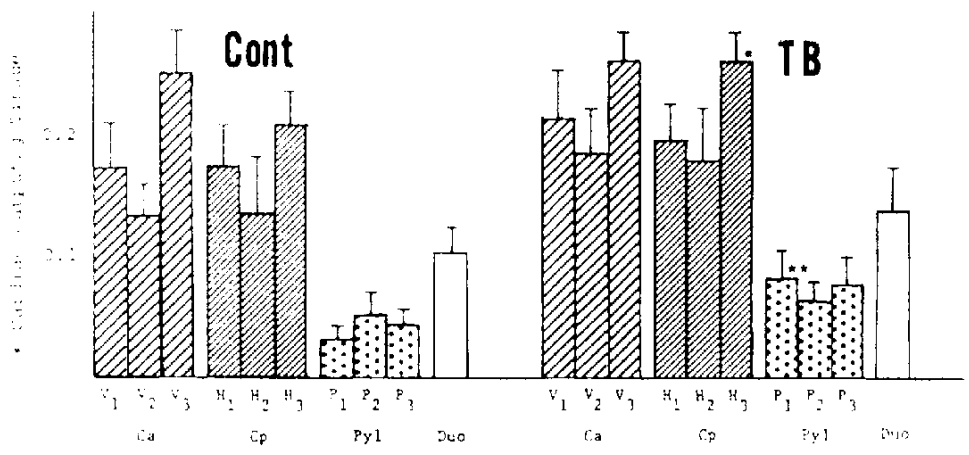

Fig. 4. Regional gastric blood flow of control or TB-treated rabbits. Vertical bars represent the mean and S.E. of 8 animals. "P<0.1, " $P<0.05$ compared with the control group.

Table 3. Tissue weight and blood flow of the mucosal and muscular layers of the gastric wall in control rabbits

\begin{tabular}{rccccccc}
\hline & \multicolumn{3}{c}{ Tissue Weight } & Blood Flow \\
& $\begin{array}{c}\text { Aretrior } \\
\text { Corpus } \\
(\%)\end{array}$ & $\begin{array}{c}\text { Posterior } \\
\text { Corpus } \\
(\%)\end{array}$ & $\begin{array}{c}\text { Pyloric } \\
\text { Antrum } \\
(\%)\end{array}$ & $\begin{array}{c}\text { Whole Stomach } \\
(\%)\end{array}$ & $(\mathrm{g})$ & (\%) & $(\%$ of C.0.) \\
Mucosal Layer & 69.2 & 67.6 & 34.8 & 59.6 & $12.91 \pm 1.19$ & 84.0 & $2.78 \pm 0.32$ \\
Muscle Layer & 30.8 & 32.4 & 65.2 & 40.4 & $8.74 \pm 0.71$ & 16.0 & $0.53 \pm 0.13$ \\
\hline
\end{tabular}

Values represent the mean and S.E. of 8 animals. 
antrum $(P<0.05)$ and $H_{3}$ of the posterior corpus (Fig. 4). Therefore, TB tended to lessen the differences in regional gastric blood flow.

Effect of TB on gastric blood flow under the influence of cholinergic drugs

When rabbits were pretreated with TB

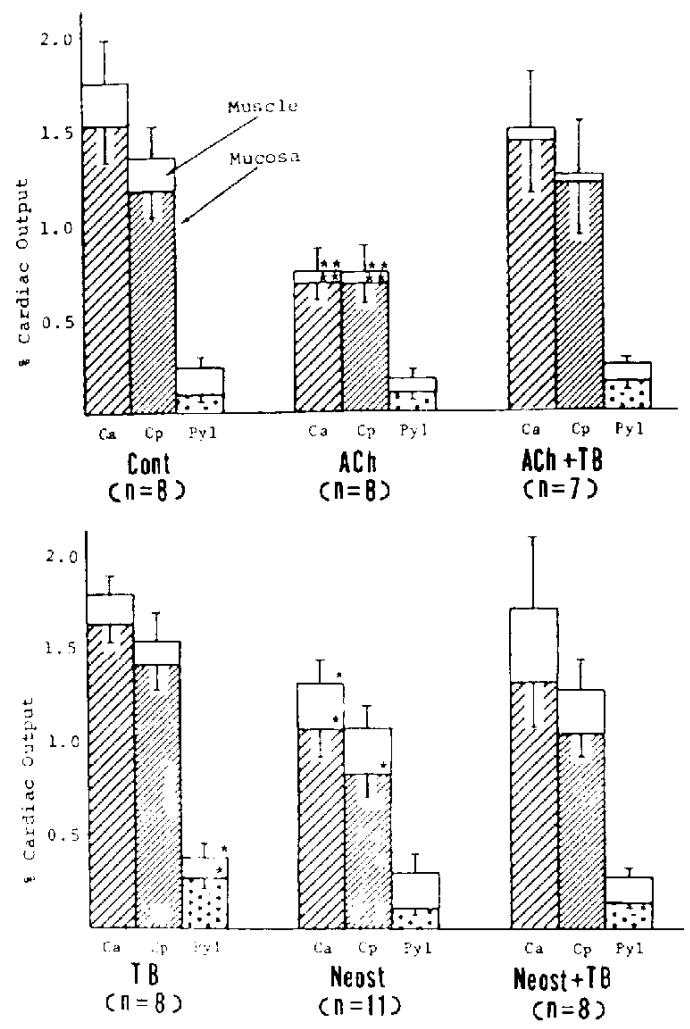

Fig. 5. Regional blood flow in the stomach of the rabbits treated with various drugs: saline (Cont) $200 \mu \mathrm{g} / \mathrm{kg}$ TB, $10 \mu \mathrm{g} / \mathrm{kg}$ ACh, $50 \mu \mathrm{g} / \mathrm{kg}$ Neost, $A C h+T B$ and Neost+TB. Vertical bars represent the mean and S.E. of 11 animals. ${ }^{*} \mathrm{P}<0.1$, ${ }^{*} \mathrm{P}<0.05$ compared with the control group. before ACh treatment, blood flow increased $98.5 \%$ in the anterior corpus $(\mathrm{P}<0.05)$. $66.4 \%$ in the posterior corpus $(P<0.1)$, and $36.4 \%$ in the pyloric antrum from the levels obtained after ACh treatment alone (Fig. 5). The increases in mucosal blood flow in the anterior corpus, posterior corpus, and antrum were $106.4 \% \quad(P<0.05)$. 74.0\% $\quad(P<.0 .1)$. and $57.7 \%$, respectively. Both mucosal and muscular blood flow in $V_{3}$ markedly increased. especially in the mucosal layer $(P<0.05$. data not shown). There were no significant differences from the blood flows of normal rabbits, and therefore. TB virtually abolished the effect of $A C h$ on gastric blood flow ( $P<0.05$. Fig. 5).

Effects of TB on blood flow in the stomach of rabbits treated with Neost were also examined. As shown in Fig. 5, no significant difference in gastric blood flow was observed in comparison with the control levels, indicating that TB also abolished the effect of Neost.

Effects of the drugs on duodenal blood flow

Since it was difficult to separate the mucosal layer from the muscular layer in the duodenal wall of rabbits, blood flow in the duodenum was measured as a whole. As shown in Table 4, blood flow in the duodenum of rabbits treated with cholinergic or anticholinergic drugs showed little difference from the control in contrast with the stomach.

\section{DISCUSSION}

For the measuremant of gastric blood flow. 1311-MAA was used because it has the same

Table 4. Duodenal blood flow distribution ( $\%$ of the cardiac output/g tissue) of the rabbits in various experimental groups

\begin{tabular}{ccccccc}
\hline Drugs & Control & TB & $\mathrm{ACl}$ & $\mathrm{ACh}+\mathrm{TB}$ & Neost & Neost $+\mathrm{TB}$ \\
$\mathrm{n}$ & 8 & 8 & 8 & 7 & 11 & 8 \\
Duodenal & 0.11 & 0.14 & 0.11 & 0.12 & 0.16 & 0.14 \\
Blood Flow & \pm 0.02 & \pm 0.03 & \pm 0.02 & \pm 0.03 & \pm 0.03 & \pm 0.03 \\
\hline
\end{tabular}

Each value represents the mean and S.E. of 7 to 11 animals. 
specific gravity as serum and can be mixed with blood completely (7). This enabled us to measure the total and regional blood flow in organs simultaneously. Total blood flows in various organs obtained by the 131/-MAA method were in good agreement with those obtained by the radioactive microsphere technique (11), showing the validity of this method.

When gastric and duodenal blood flows were determined in normal rabbits by the use of 131/-MAA, differences between various regions of the stomach were observed by means of both radioassay and autoradio graphy. There was a considerable difference in blood flow between the pyloric antrum and the corpus or duodenum and a slight difference between the anterior and posterior corpus (Table 2). Delaney and Grim (12). using a $42 \mathrm{~K}$ clearance technique, found that in normal dogs the blood flows in the corpus and antrum were $89 \%$ and $11 \%$ of the total gastric flow, respectively. Asano et al. (8). using $1311-M A A$, reported that in normal rabbits the relative blood flow in the anterior corpus, posterior corpus, and pyloric antrum was 1.71 .1 .38 and 1.0. respectively. Our results are in good agreement with their data. The finding that the border segments $\left(V_{2}\right.$, $\mathrm{H}_{2}$ ) corresponding to the lesser curvature had a poorer supply of blood flow than $V_{3}$ and $\mathrm{H}_{3}$ of the corpus seems to be in accord with the report of Atari (13) that the peptic ulcer on the lesser curvature side is more likely to recur and enduring inflammation is more apt to take place in these regions because of lesser vascular distribution as compared with the rest of the corpus. As shown in Table 3 , the blood flow in the mucosal layer of the stomach was much greater than that in the muscular layer, occupying more than $80 \%$ of the total gastric blood flow. This indicates that the microcirculatory system of the mucosal layer of the stomach plays an important role as the defensive site against gastric ulcers.

$\mathrm{ACh}$ and Neost have been shown to cause contraction of the smooth muscle of the gastric wall, vasodilation of the peripheral vessels, and stimulation of the secretion of gastric juice (14). In the present experiment. $A C h$ did not increase the blood flow in the acid secreting regions of the gastric mucosa. but instead it remarkably reduced the total gastric blood flow. Asano et al. (8) reported that $\mathrm{ACh}$ extremely increased the gastric blood flow. This discrepancy could be explained partly by the difference in the route of administration of the drug. We administered $\mathrm{ACh}$ to rabbits intravenously. whereas their route of administration was subcutaneous. No precise descriptions about the injected dose and other procedures are given in their report. It is conceivable that in our experiment ACh may have caused predominantly extravascular contracture (i.e.. contraction of the gastric wall) rather than vasodilation. In the case of Neost, an inhibitor of cholinesterase, a similar tendency of reduction in blood flow was demonstrated but it was less prominent than in the case of ACh.

In cholinergic drug-treated animals, TB abolished the effects of these drugs on blood flow and restored the reduced blood flow to the normal level. Since TB is considered to act primarily on the muscarinic sites (3). the above effect of TB may be mediated by its action on these sites.

When TB was injected into normal rabbits. TB considerably increased the blood flow in the mucosal laver of the regions with thick muscular layers such as the pyloric antrum (Fig. 4, Table 3), although there was only a slight increase in total gastric blood flow. These results may be mainly ascribable to the relaxation of the tonus of the gastric wall caused by the inhibitory effect of TB on spontanous motility of the stomach (1). However, the possibility of a direct action of 
this compound on the mural and vascular smooth muscles in the stomach cannot be denied. Tamaki in this laboratory demonstrated that the contracture induced by $\mathrm{K}^{+}$depolarization was relaxed by relatively high doses of TB in the taenia coli of guinea pigs (H. Tamaki, unpublished observation).

TB has an anti-ulcerogenic effect which may be due to the inhibitory effects on gastric motility and secretion. With respect to the gastric blood flow, however. TB tended to increase blood flow in the pyloric antrum. especially in the mucosal layer and to lessen the regional difference of blood flow in the stomach. TB also recovered the gastric blood flow reduced by $\mathrm{ACh}$ or Neost to the control level. It may be proposed from these findings that TB affects the blood flow of the microcirculatory system of the stomach which is one of the defensive factors against ulceration (5).

Compared to the gastric blood flow, the duodenal blood flow was not significantly affected by these cholinergic or anticholinergic drugs. The anti-ulcerogenic effect of TB in the duodenum was difficult to relate to the duodenal blood flow. In the duodenum, it may largely be attributed to the inhibitory effect of TB on gastric secretion.

Acknowledgements: The authors are grateful to Dr. A. Kiyomoto, Director of this laboratory, for constant encouragement throughout these studies. Gratitude is also due to Drs. H. Nakajima, S. Takeyama and H. Tamaki for helpful discussions and Miss N. Ogihara and Mrs. M. Choei for technical assistance.

\section{REFERENCES}

1) Tamaki, H., Ikeo, T., Harigaya, S. and Nakajima, $H$.: Effect of a new anticholinergic agent (SA504) on motility of the gastrointestinal tract and the urinary bladder in cats. Japan. J. Pharmacol. 23, 391-400 (1973)

2) Tamaki, H. and Saito, K.: Pharmacological actions of timepidium bromide on the motility of visceral smooth muscles and the secretion of digestive juice in experimental animals. Folia pharmacol. japon. 74, 559-571 (1978) (Abs. in English)

3) Tamaki, H., Tanaka, M., Murata, S., Harigaya, S. and Kiyomoto, A.: Pharmacological properties of a new anticholinergic agent, 1.1-dimethyl5-methoxy-3-(dithien-2-ylmethylene) piperidinium bromide (SA-504). Japan. J. Pharmacol. 22, 685-699 (1972)

4) Omata, S., Imamura, K., Osada, M., Koizumi, H., Kurita, K., Mimoto, S., Nose, T., Ohshita, T., Kohda, Y. and Shimura, M.: Clinical trials of timepidium bromide (SA-504) for the treatment of abdominal pain in gastrointestinal diseases (a double-blind controlled trial). Clinical Evaluation 2, 69-104 (1974) (Abs. in English)

5) Shay, H.: Etiology of peptic ulcer. Am. J. Digest. Dis. 6, 29-49 (1961)

6) Goldman, H. and Rosoff, C.B.: Pathogenesis of acute gastric stress ulcers. Am. J. Pathol. 52, 227-243 (1968)

7) Ueda, H., Kaihara, S., Ueda, K., Sugishita, $Y$., Sasaki, $Y$. and lio, M.: Regional myocardia blood flow measured by 131 l-labelled macroaggregated albumin (131-MAA). Japan. Heart J. 6, 534-542 (1965)

8) Asano, K., Mivake, H., Ono, M., Fukutome, $M$. and Takano, M.: Genesis and treatment of gastric ulcer in view point of gastric blood flow. Kiso to Rinsho 8, 3565-3572 (1974) (in Japanese)

9) Sato, Y. and Abe, K.: The essential points on preparation of whole body autoradiogram (1). Pharmacometrics 3, 1-6 (1969) (Abs. in English)

10) Sato, $Y$. and Abe, K.: The essential points on preparation of whole body atutoradiogram (11). Pharmacometrics 3, 77-88 (1969) (Abs. in English)

11) Neutz, J.M., Wyler, F. and Rudolph, A.M.: Use of radioactive microspheres to assess distribution of cardiac output in rabbits. Am. J. Physiol. 215, 486-495 (1968)

12) Delaney, J.P. and Grim, E.: Canine gastric blood flow and its distribution. Am. J. Physiol. 207, 1195-1202 (1964)

13) Atari, H.: Morphological analysis of gastrointestinal disease on the basis of normal organ vasculature. Stomach and Intestine 14, 593605 (1979) (Abs. in English)

14) Koelle, G.B.: Parasympoathmimetic agents. In The Pharmacological Basis of Therapeutics. Edited by Goodman, L.S. and Gilman. A., Ed. 5. p. 467, The Macmillan Publishing Co., Inc., New York (1975) 